\title{
High D-dimer Level in Fracture Patient with Asymptomatic Covid-19: Dilemmatic Surgery Decision - A Serial Case Report
}

\author{
I Made Wira Kusuma ${ }^{1}$, I Made Iman Antariksa ${ }^{2}$, \\ Ida Bagus Gde Darma Wibawa ${ }^{2}$, Made Wahyu Dharmapradita ${ }^{2}$, \\ Kadek Yuris Wira Artha ${ }^{2}$, Ni Gst Putu Arini Junita Putri Kardinal ${ }^{3}$ \\ ${ }^{1}$ Intern of Orthopaedic and Traumatology Department, Mangusada Hospital, Indonesia \\ ${ }^{2}$ Orthopaedic and Traumatology Specialist of Orthopaedic and Traumatology Department, Mangusada Hospital \\ ${ }^{3}$ Consultant of Hematology and Oncology, Internal Medicine Department, Mangusada Hospital
}

Corresponding Author: I Made Wira Kusuma

\begin{abstract}
Introduction: SARS-CoV-2 is highly transmittable virus. D-dimer associated with high fatality rate in COVID-19 with pneumonia and fractures. COVID-19 makes surgical decision more challenging. Thrombosis plays an important mechanism in severity of COVID-19 and could be measured through D-dimer level.

Case illustrations: We report 4 fracture cases with asymptomatic COVID-19. $1^{\text {st }}$ case diagnosed close fracture in right $1 / 3$ distal cruris without pneumonia, D-dimer $2420 \mathrm{ng} / \mathrm{dl}$. Surgery 20 days after trauma with decreased Ddimer level. $2^{\text {nd }}$ case, was diagnosed with close fracture in the left cruris and right $1 / 3$ middle of clavicle with pneumonia, D-dimer level 6670 $\mathrm{ng} / \mathrm{dl}$, decision obtained in 27 days after hospitalization with decreased D-dimer. $3^{\text {rd }}$ case diagnosed open fracture in left $1 / 3$ distal humerus with pneumonia, D-dimer level 1020 $\mathrm{ng} / \mathrm{dl}$. Surgery 32 days after trauma with decreased D-dimer. $4^{\text {th }}$ case diagnosed open fracture in left $1 / 3$ proximal humeral and left medial phalanx index finger with pneumonia. The D-dimer level $2830 \mathrm{ng} / \mathrm{dl}$. Surgery was obtained 17 days after trauma with decreased Ddimer.
\end{abstract}

Discussion: Pandemic creates gray zone in orthopedic surgery. D-dimer found increased in COVID-19 and fracture patients. Asymptomatic case can be operated on $10^{\text {th }}$ day post positive result as long as the general condition is optimal. D-dimer also important in making the decision to perform surgery. D-dimer over 2500 $\mathrm{ng} / \mathrm{mL}$ have greater risk for being VTE in fracture patients.

Conclusion: The pandemic has creates a large gray zone. The strategies for decision making includes general condition and severity COVID19 also D-dimer level.

Keywords: D-dimer, COVID-19, Fracture, Surgery

\section{INTRODUCTION}

The severe acute respiratory syndrome corona virus 2 (SARS-CoV-2), first spread from its origin in China then all around the world. ${ }^{1}$ Per September 2021, the Government of Indonesia has reported more than 4.147.365 persons with confirmed COVID-19, which dominated by asymptomatic patients. ${ }^{2,3}$ With all the severity it cause, COVID-19 have heavily impacted all specialities which not directly related to clinical effects such as orthopedic.

Thrombosis plays important mechanism of severity in COVID-19 and measured through biomarkers, including Ddimer. ${ }^{3}$ Moreover, high level D-dimer would be corresponding indicators of fractures in patients with COVID-19. Study found relation between COVID-19 and fractures could lead to adverse outcomes and mortality. ${ }^{4}$ Unfortunately the D-dimer level examination isn't always available either. Therefore, many scoring systems are 
developed to predict VTE in hospitalized patient. The existing scoring systems are caprini RAM, padua score and many more. ${ }^{5}$ Caprini RAM accurately predict risk of inhospital patient undergoing surgery and 6month mortality among VTE than others. It was more sensitive in able to identify patients who needed prophylaxis. ${ }^{6}$ Identification involves a potential risk of bleeding and implementation of risk assessment models (RAM) are essensial to ensure correct use of thromboprophylaxis such as IMPROVE (International Medical Prevention Registry on Venous Thromboembolism) bleeding risk score.

Decision for surgery on fracture patients is a challenge for orthopedic surgeons in this pandemic era. Especially for COVID-19 case with increased levels of D-dimer. Elective surgical procedures on fractures postponed to decrease health system burden and allows more bed occupancy rate. ${ }^{4}$ Despite the urgency of COVID-19 control in fracture cases, low availability of information regarding COVID-19 in orthopedic centers. ${ }^{7}$

\section{SERIAL CASE REPORT Case Report 1}

58 years old woman admitted to emergency room with pain in her right lower leg after a motorbike accident. She was conscious and had normal vital sign (blood pressure: 120/80; heart rate: 74 bpm; respiration rate: $18 \mathrm{bpm}$; temperature: $36,7^{\circ} \mathrm{C} ; \mathrm{SpO}_{2}: 98 \%$ ). On examination, the patient complained swelling, deformity, tenderness, crepitation and no limited motion. The radiograph shown fracture in right $1 / 3$ distal cruris region without pneumonia were discovered. The nasopharyngeal RT- PCR SARS-CoV-2 test with positive result with no symptoms of COVID-19. She was treated to the COVID19 isolation unit.

Patient get $40 \mathrm{mg}$ enoxaparin injection twice a day until 24 hours before surgery due to her elevated D-dimer level $(2420 \mathrm{ng} / \mathrm{dl})$. The condition was stable and showed no additional symptoms. After 10 days administration of antiviral, evaluation RT- PCR SARS-CoV-2 test was performed with negative result. Surgery decision with ORIF PS on tibia and fibula was obtained 20 days after trauma with negative swab results and decreased D-dimer $(1890 \mathrm{ng} / \mathrm{dl})$. Patient was continued given 4250 IU injection of anticoagulant parnaparin once a day and was admitted to the intensive care unit for vein thromboembolic symptoms.

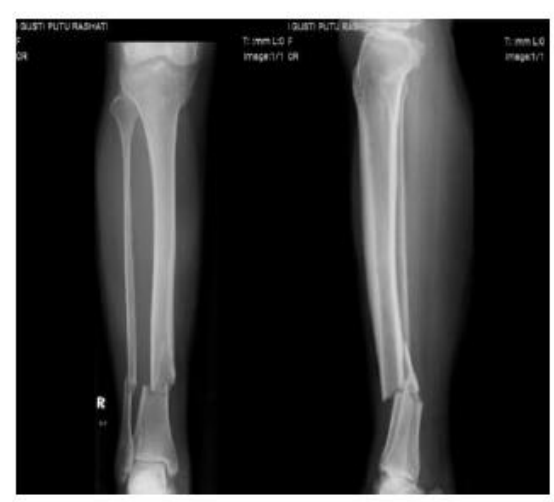

Preoperative Cruris x-rav AP \& Lat view

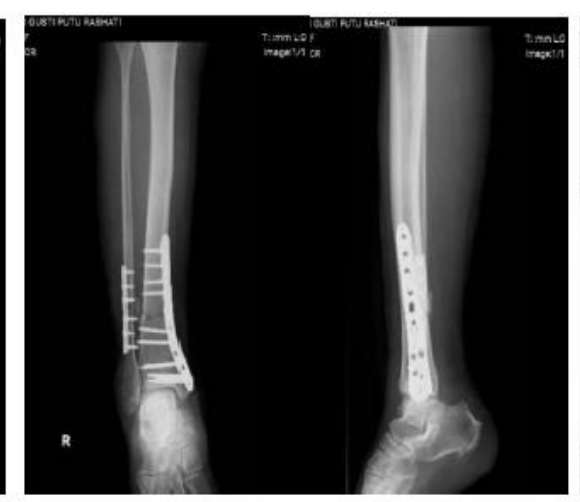

Post-operative cruris x-rav AP \& Lat view

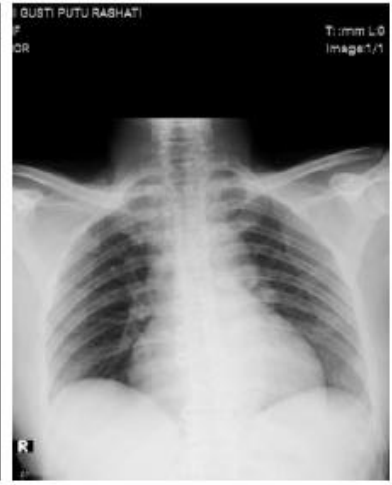

Chext X-Ray AP view

\section{Case Report 2}

49-year-old woman was admitted to emergency room with pain in her left lower leg and right shoulder after a motorbike accident. She was conscious and had normal vital sign (blood pressure: 110/70; heart rate: 88 bpm; respiration: 20 bpm; temperature: $36,6^{\circ} \mathrm{C} ; \quad \mathrm{SpO}_{2}: 97 \%$ ). On examination, the patient complained of swelling and deformity, tenderness, crepitation with no limited motion. The radiograph shown segmental fracture in the 
left cruris region and a fracture in the right $1 / 3$ middle of clavicle. Bilateral pneumonia were discovered on chest $\mathrm{x}$-ray. The nasopharyngeal RT- PCR SARS-CoV-2 swab test with positive result with no symptoms of COVID-19. She was treated to the COVID-19 isolation unit

Patient was given $5 \mathrm{mg}$ fondaparinux once a day until 24 hours before surgery for elevated D-dimer level (6670 ng/dl). The patient was stable and showed no additional symptoms. However, the patient's RT- PCR SARS-CoV-2 swab test results were never negative and, surgery decision with ORIF PS on tibia obtained in 27 days after hospitalization with positive swab results and decreased D-dimer level $(2710 \mathrm{ng} / \mathrm{dl})$. Conservative management with immobilization is performed on the clavicle fracture. Patient was continued given $5 \mathrm{mg}$ injection of anticoagulant fondaparinux once a day and was admitted to the COVID-19 unit for vein thromboembolic symptoms.
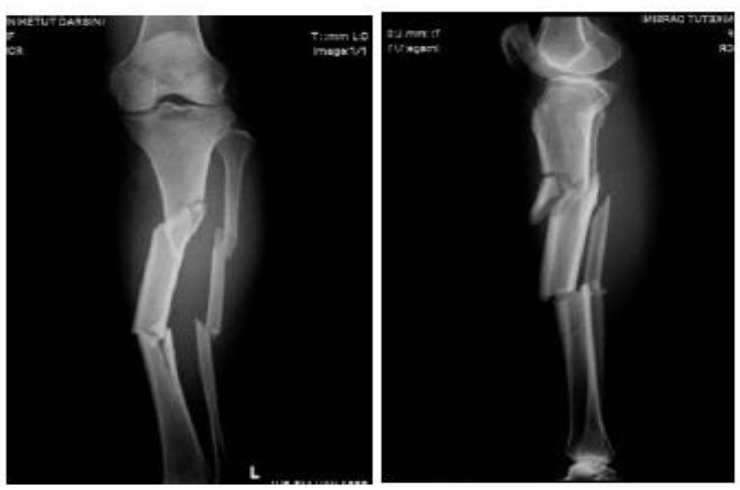

Preoperative Cruris x-ray Ap \& lat View
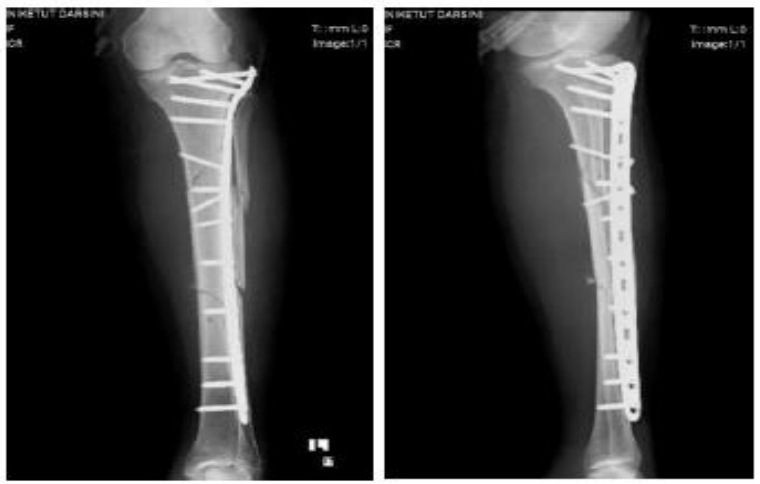

Prostoperative Cruris x-ray Ap \& lat View

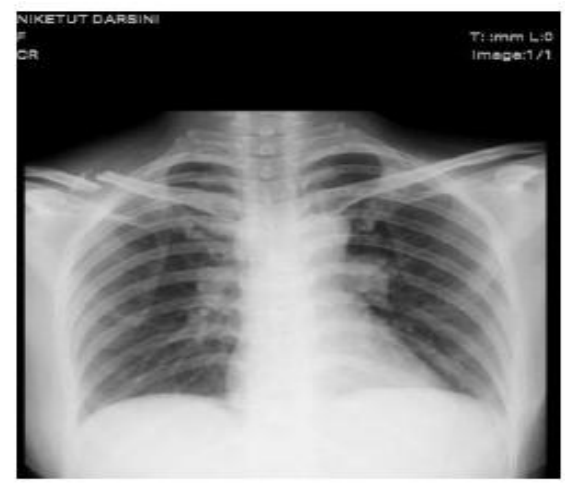

Chest x-ray Ap View

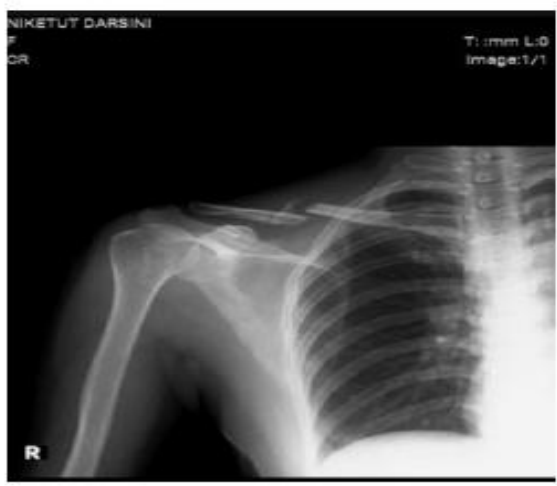

Shoulder x-ray Ap View

\section{Case Report 3}

A 47-year-old man admitted to the emergency room with pain and open sores in his left upper arm after a motorbike accident. He was conscious and had normal vital sign (blood pressure: 110/80; heart rate: $94 \mathrm{bpm}$; respiration rate: $18 \mathrm{bpm}$; temperature: $36^{\circ} \mathrm{C} ; \mathrm{SpO}_{2}: 97 \%$ ), patient is an active smoker. The patient complained of swelling, open wound, deformity, tenderness, crepitation, and no limited motion. The radiograph shown fracture in left one third distal humeral region with bilateral pneumonia. The nasopharyngeal RT- PCR test with positive result with no symptoms of COVID-19. He was then treated to the COVID-19 unit.

Patient was given $40 \mathrm{mg}$ enoxaparin twice a day for elevated D-dimer level (1020 ng/dl). The patient was stable. After 10 days administration of antiviral, evaluation RT- PCR SARS-CoV-2 swab test was positive and D-dimer level 3360 $\mathrm{ng} / \mathrm{dl}$. The surgeon finally decided to instruct the patient's home isolation by backslab immobilization. Five days later the 
patient came for surgery with a negative RT-PCR swab test result but an increase Ddimer level $(3650 \mathrm{ng} / \mathrm{dl})$. Surgery decision with ORIF PS obtained in 32 days after trauma with negative swab results and decreased D-dimer level (1090 ng/dl). Patient was continued given $40 \mathrm{mg}$ enoxaparin once a day and admitted to the free COVID-19 ward for vein thromboembolic monitoring.
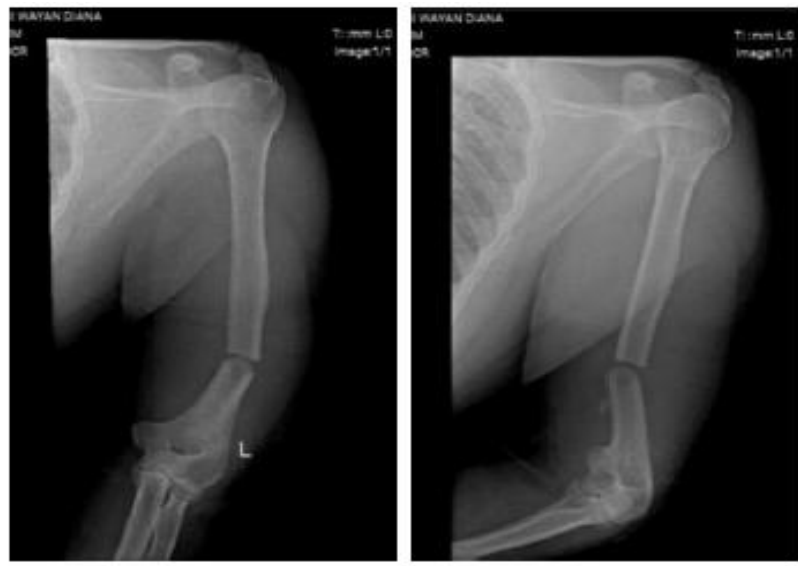

Preoperative Humerus X-ray Ap \& Lat view
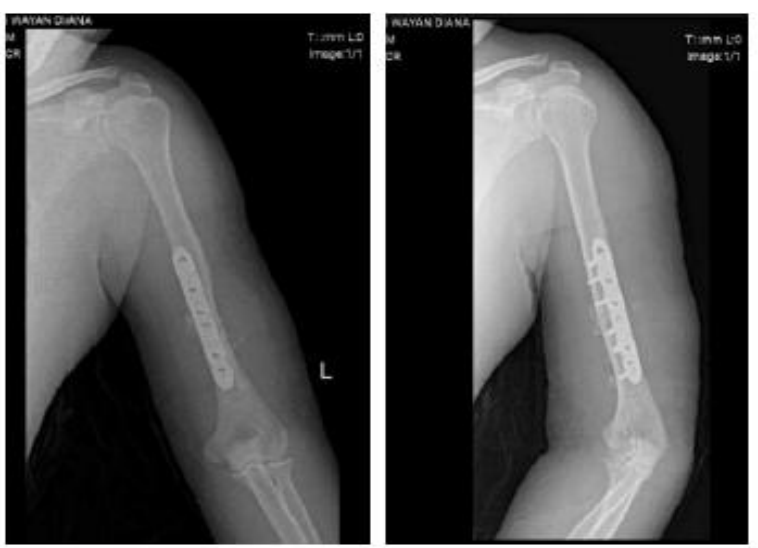

Postoperative Humerus X-ray Ap \& Lat view

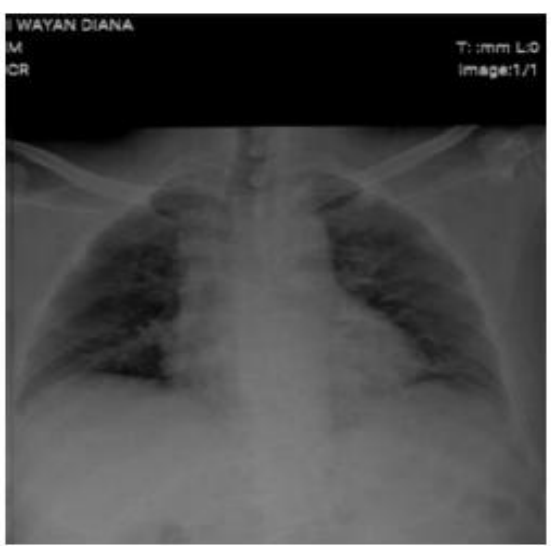

Chest $\mathrm{X}$-ray Ap view

\section{Case Report 4}

50-year-old woman admitted to the emergency room with pain and open sores in his left upper arm and index finger after a motorbike accident. She was conscious and had normal vital sign (blood pressure: 120/70; heart rate: $82 \mathrm{bpm}$; respiration rate: $20 \mathrm{bpm}$; temperature: $36^{\circ} \mathrm{C} ; \mathrm{SpO}_{2}$ : $98 \%$ ). On examination, the patient complained of swelling, open wound, deformity, tenderness, crepitation with no limited motion in the left humeral and left phalanx index finger. The radiograph shown fracture in left $1 / 3$ proximal humeral and left medial phalanx index finger with bilateral pneumonia. The Nasopharyngeal RT- PCR test with positive result with no COVID-19 symptoms. She was then treated to the COVID-19 unit.

Patient was given $40 \mathrm{mg}$ enoxaparin twice a day until 24 hours before surgery for her elevated D-dimer level (2830 ng/dl). The patient was stable and showed no additional symptoms. After 14 days hospitalized, evaluation RT- PCR test was performed with negative result but yet got surgery, due to Haemoglobin improvement. Surgery obtained with ORIF PS on humerus and ORIF Pininng on medial phalanx index finger was obtained 17 days after trauma, with D-dimer level 1000 ng/dl. Anticoagulant injection was discontinued after surgery and she admitted to the high care unit for vein thromboembolic symptoms. 
I Made Wira Kusuma et.al. High D-dimer level in fracture patient with asymptomatic Covid-19: dilemmatic surgery decision-a serial case report

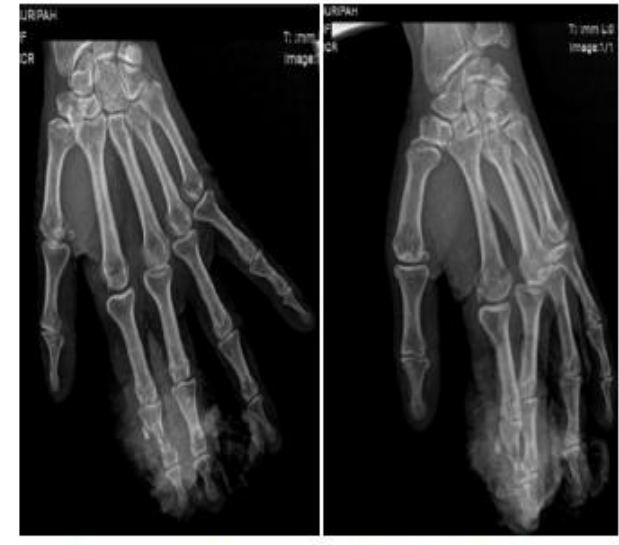

Preoperatif Man us X-ray Ap \& Oblique view
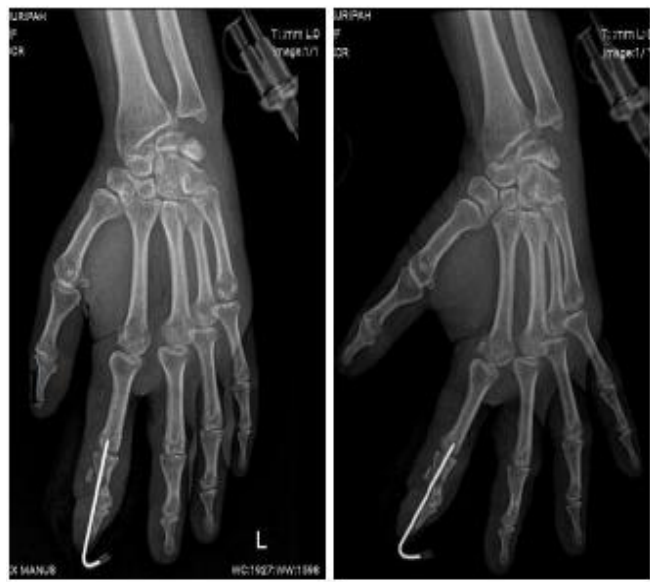

Postoperatif Manus X-ray Ap \& Oblique view

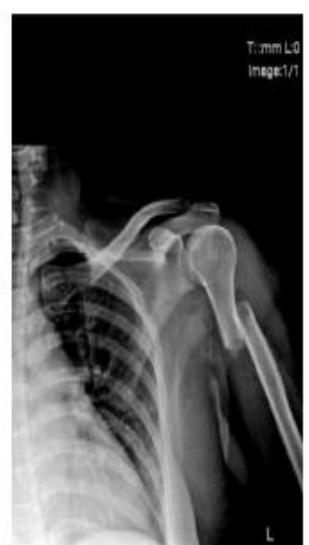

Preoperatif Shoulder X-ray AP view

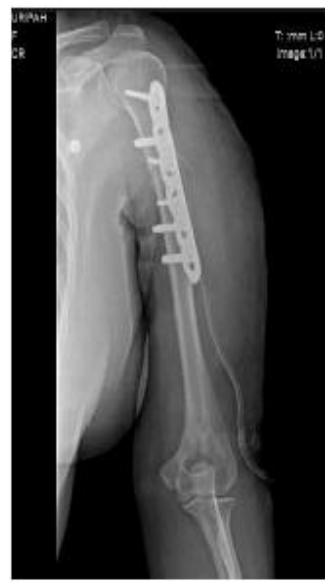

Postoperatif Humerus X-ray Ap \& Lat view

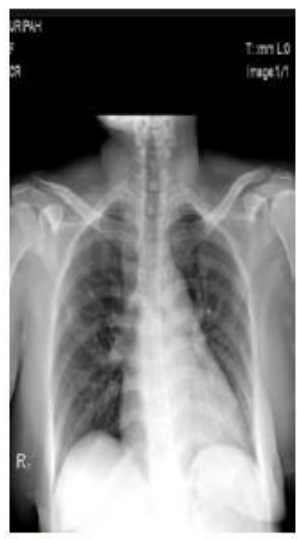

Chest X-ray AP view

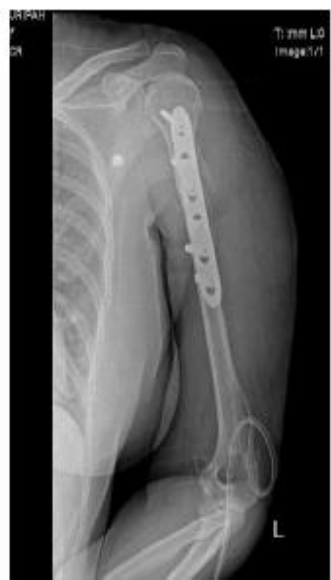

nembete Math$$
\text { . }
$$
.

Table 1: Patient's status

\begin{tabular}{|c|c|c|c|c|c|c|c|c|}
\hline Case & $\begin{array}{l}\text { Type of } \\
\text { fracture }\end{array}$ & $\begin{array}{c}\text { First } \\
\text { D-dimer }\end{array}$ & $\begin{array}{l}\text { Highest } \\
\text { D-Dimer }\end{array}$ & $\begin{array}{c}\text { Preop } \\
\text { D-dimer }\end{array}$ & $\begin{array}{c}\text { Status during } \\
\text { surgery }\end{array}$ & $\begin{array}{l}\text { Surgery } \\
\text { decision }\end{array}$ & $\begin{array}{c}\text { Caprini } \\
\text { RAM }\end{array}$ & $\begin{array}{c}\text { IMPROVE } \\
\text { BRS }\end{array}$ \\
\hline $\begin{array}{l}\text { Case } 1 \\
\text { W-58 y.o }\end{array}$ & $\begin{array}{l}\text { CF Tibia } \\
\text { CF Fibula }\end{array}$ & 2420 & 4400 & 1890 & $\begin{array}{c}\text { Negatif } \mathrm{C} 1 \\
9\end{array}$ & 20 days & 13 points & 1.5 points \\
\hline $\begin{array}{l}\text { Case } 2 \\
\text { W-49 y.o }\end{array}$ & $\begin{array}{l}\text { CF Tibia } \\
\text { CF Fibula } \\
\text { CF Clavicle }\end{array}$ & 6670 & 6670 & 2710 & Positif C19 & 26 days & 19 points & 1.5 points \\
\hline $\begin{array}{l}\text { Case } 3 \\
\text { M-47 y.o }\end{array}$ & OF Humerus & 1020 & 3650 & 1090 & Negatif C19 & 32 days & 8 points & 2.5 points \\
\hline $\begin{array}{l}\text { Case } 4 \\
\text { W-50 y.o }\end{array}$ & $\begin{array}{l}\text { OF Humerus } \\
\text { OF Medial } \\
\text { Phalanx }\end{array}$ & 2830 & 4330 & 1000 & Negatif $\mathrm{C} 19$ & 17 days & 12 points & 5.5 points \\
\hline
\end{tabular}

\section{DISCUSSION}

From cases above, all surgery were postponed due to positive result on RTPCR test with asymptomatic case. To determine which procedure to proceed is challenging. At pandemic era, it is crucial to provide which better procedures to choose. Might be sketchy but this era has made all aspect become complex, creating a large gray zone. With no algorithm agreed in the community, it would be wise to make individualized to each centers. Awad et al. stratified orthopedic conditions into five categorized according to urgency, A through E, A being the most urgent. Open fracture, acute neurovascular derangements were rendered as emergent (A) to be operated within 24 hours. Closed fractures were grouped under B or C. ${ }^{4}$

All patients undergo D-dimer testing. Patients which tested positive were reported to have a hypercoagulable state. ${ }^{8}$ D-dimer levels are commonly high in patients infected with COVID-19. Higher levels found in patient with critical illness 
and may be used as a prognostic marker for in-hospital mortality. ${ }^{9}$

Elevated D-dimer also found in fractures. Based on the study, fractures of different region showed diversity D-dimer levels, which femoral fracture was the above off all. Long bone fracture trigger higher level of D-dimer than short bone, and the severity of the trauma might affect the level of D-dimer in plasma. Elevated Ddimer in plasma of fracture case must be monitored and need thrombosis prevention. Bleeding risk also increase after thrombosis due to coagulation. ${ }^{10}$ Through D-dimer analysis among patients with fractures, found that value of the D-dimer is positively correlated with fractures. The more fractures occurred in a patient, the higher D-dimer is. Thus, D-dimer can be an indicator of the severity of trauma. ${ }^{11}$ In line with this, the second case which is a case of multiple fractures (involving three bones) has the highest D-dimer compared to the third case which only had one bone fracture, even though the third case was an open fracture.

All patient are measured by Caprini score. The Caprini Risk Assessment Models (The Caprini RAM) was a wighted risk model which creates an aggregate risk score based on presence or absence of 39 individual risk factors. Based on it, patients are grouped into VTE categories: low risk which scored 0 to 4 require no VTE prophylaxis, moderate risk (score of 5 to 8 ) and high risk (score of 9 or more) receive 10 and 30 days of extended prophylaxis, respectively. ${ }^{12}$

Besides Caprini RAM, The American College of Chest Physicians guidelines for antithrombotic therapy and prevention of thrombosis $9^{\text {th }}$ editon adopted the Padua Prediction Score (PPS) for evaluating the risk of VTE in medical inpatients. Zhou et al states that Caprini RAM accurately predict risk of inhospital and mortality among VTE patients rather than PPS. It means the scoring shown higher sensitivity for high risk identification than PPS. High sensitivity of this scoring attributed mostly to the comprehensive risk factor which includes: 39 known risk factors of VTE in the Caprini RAM vs. 11 risk factors in the PPS. Almost all the factors in the PPS can be seen in the Caprini RAM, with some in slightly different form or with slightly different definitions. ${ }^{12}$ The first, second, and fourth case are categorized with high risk VTE, meanwhile the third case had moderate risk VTE. The other study, Wirabhawa et al. showed there is a positive relationship between the Caprini Score and D-Dimer with cut-off point Caprini score of 8 is equivalent to D-dimer $>7.2 \mathrm{ug} / \mathrm{ml}$ as predictor of DVT risk in post-fixation patients internal fractures of the long bones of the lower extremities. ${ }^{6}$ Pannuci et al. also show that the benefit thromboprophylaxis only shown in surgical patients with Caprini score above seven points. ${ }^{13}$

Appropiate medication with individualized VTE risk grouping helps determine the thromboprophylaxis is done in exact surgical patients and might decrease complications. ${ }^{13}$ All cases were administrated Low Molecular Weight Heparin (LMWH) because there's an elevated of D-dimer level and improve Bleeding Risk Score $<7$ points. Which support the high Caprini RAM score of each patient, so that anticoagulation is considered as prophylaxis to prevent VTE. The principal RAM for bleeding associated with pharmacological prophylaxis in hospitalized medical patients is the IMPROVE BRS. Risk factors at admission which related with risk of bleeding were active gastrointestinal ulcer, bleeding during the 3 months preceding admission, and platelet count $<50.000 / \mathrm{mm}^{14}$ Others risk factors for bleeding included advanced age, liver and/or kidney failure, admission to intensive care unit, presence of a central venous catheter and cancer. IMPROVE Bleeding Risk Score of $\geq 7$ as high risk bleeding and score $<7$ as low risk. The RAM helps making decisions on pharmacological or mechanical prophylaxis in medical patients at high risk VTE. In orthopedic, estimates of initial bleeding risk in the absence of prophylaxis vary widely because of the 
heterogeneous characteristics of the populations involved and the surgical techniques employed. ${ }^{15}$ Risk of major bleeding estimated in the range of 2 to $4 \%$ for surgery with duration exceeding 45 minutes and in bilateral knee joint replacement. $^{16}$ Rates of major bleeding among patients given VTE prophylaxis varied from $0.1 \%$ to $3.1 \%$ in studies of hip joint replacement and from $0.2 \%$ to $1.4 \%$ in studies of knee joint replacement, suggesting that anticoagulants have little impact on risk of bleeding in these groups of patients. $^{17}$

All four patients were planned to undergo surgery. What makes difference is when the operating decision is made. The first case, the surgery is done 20 days post trauma (after 10 days administration of antiviral) with negative result for RT- PCR SARS-CoV-2 swab test and decreased Ddimer level. The decision surgery in second case was 26 days after trauma with positive swab result with decreased D-dimer level. Then, the third case has not been operated on because the RT-PCR SARS-CoV-2 swab test result is still positive (after 10 days administration of antiviral) and high Ddimer level. The orthopedic surgeon instructs the patient's home isolation by backslab immobilization. The surgery decision was obtained after the negative result from the swab test and decreased Ddimer level. The last case, although the RTPCR SARS-CoV-2 swab test is negative with decreased D-dimer level, the patient cannot be operated on because of low hemoglobin levels.

The patient must be examined for fever, cough and sore throat, if the mentioned symptoms appear, it is recommend to postpone management prior to result availability. If the surgery couldn't be delayed for testing, the patient should retriaged into the emergency category and presumed COVID positive (Picture 1). ${ }^{7}$

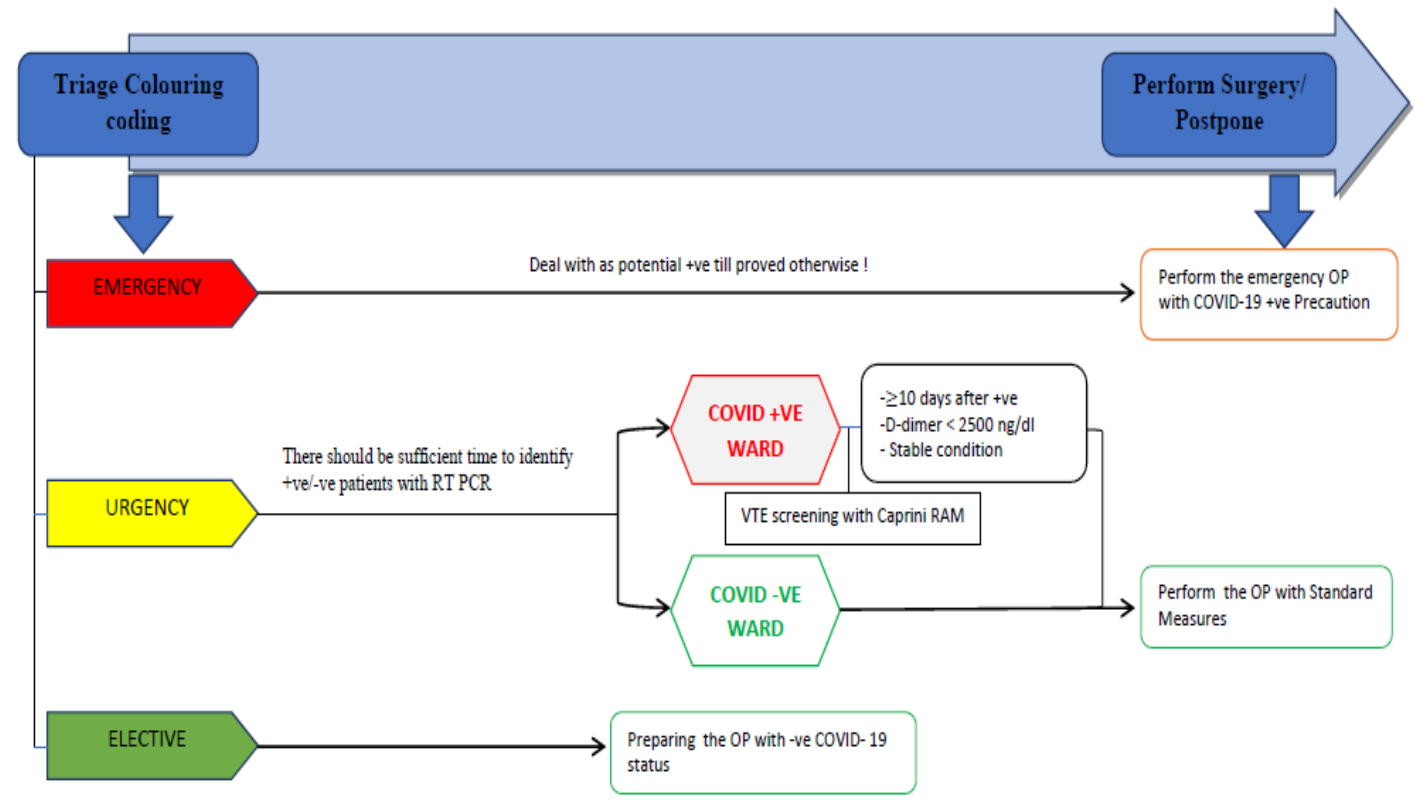

Picture 1: Algorithm for handling fracture patients with asymptomatic COVID- 19

From the cases, all the patients were undergone RT- PCR SARS-CoV-2 swab test for evaluation before surgery. For example the first case is done the swab test after 10 days receiving antiviral therapy with negative result. It is contrast to the second case that still showed positive result until the 26 days. Detection of viral RNA on
RT- PCR isn't necessarily state that the patient is infectious and spread to another. Factors which affect transmission include whether a virus is replication-competent and the patient has symptoms. ${ }^{18}$ The second case was operated on even though the swab test result was still positive. According to the study of nine COVID-19 patients with mild 
to moderate symptoms shown no SARSCoV-2 virus able to culture from nasal samples after day 8 of onset. 3 studies of patients with undisclosed or variable degree of illness states disability to culture virus after days 7-9 of onset. Based on the updated WHO recommendation, the patient was discharged ten days plus at least 3 days without symptoms and ten days after positive test for asymptomatic case. ${ }^{18}$ On other words, the asymptomatic COVID-19 case can be operated on the tenth day after testing positif for COVID-19 without having to wait for a negative swab test result as long as the general condition is optimal and appropriate D-dimer level.

D-dimer level also important in decision making to perform surgery on fracture case of positive COVID-19. All the procedure were postponed due to elevated D-dimer level. Elevated D-dimer is a serious problem in COVID-19. In a casecontrol study, 44 COVID-19 patients and 22 control samples were studied by Luca Spiezia et al. It found that patients with COVID-19 have increased D-dimer. Elevated D-dimer at first admission were have an 18-fold risk of death compared to cases with normal D-dimer levels. ${ }^{19}$ Zhou et al. reported that D-dimer level of $>1000$ $\mathrm{ng} / \mathrm{ml}$ was connected to poor prognosis in COVID-19. ${ }^{12}$ Other study states that Ddimer value of $2.025 \mathrm{ng} / \mathrm{dl}$ is an optimal probability cut-off for judging the risk of death. ${ }^{8}$ Some literature states the cause of death is thrombotic heterogeneity which indicates clinical manifestations of the disease, including VTE and PE. ${ }^{3}$

D-dimer diffused into bloodstream because their low molecular weight. For the giving anticoagulants therapy, results showed anticoagulants might recommended in patients with D-dimer higher than 3.543 $\mathrm{g} / \mathrm{L}$. It is considered that administer anticoagulant treatments for orthopedic surgery according to fibrinogen and Ddimer levels can be done. ${ }^{20}$ In a study conducted by Levy and colleagues, 2 cut-off values were significant for the detection of DVT among posttraumatic patients, with levels less than $2500 \mathrm{ng} / \mathrm{mL}$ having a negative predictive value of $100 \%$ indetecting DVT, values greater than 2500 $\mathrm{ng} / \mathrm{mL}$ needed further evaluation. ${ }^{21}$ This is in line with research by Lin et al., that showed that the level of D-dimer over 2500 $\mathrm{ng} / \mathrm{mL}$ have greater risk for being VTE In fractur patients. ${ }^{20}$

From the cases above, all the surgery decision are ORIF PS. Especially for second case, patient with segmental tibial fractur, theoretically if the patient's condition is stable with normal D-dimer levels, the best option is to do intramedullary nailing. However, in this patient, due to the high level of D-dimer, the surgical decision was made with ORIF PS. Intramedullary nailing is the preferred course of care for the definitive management of long bone fractures. $^{22}$

\section{CONCLUSION}

The pandemic creates large gray zone in the orthopedic community. The strategies for decision making must based on general condition and severity of coronavirus infection. D-dimer examination isn't always available either. Therefore, many scoring systems are developed to predicted VTE in hospital patients and to identify who needed prophylaxis like Caprini RAM. In fracture patient with asymptomatic cases decision making surgery can be considered if has been 10 days after positive test and D-dimer level less than $2500 \mathrm{ng} / \mathrm{mL}$.

\section{Acknowledgement: None}

\section{Conflict of Interest: None}

\section{Source of Funding: None}

\section{REFERENCES}

1. Singhal, Tanu. 2020. A Review of Coronavirus Disease-2019 (COVID-19). The Indian Journal of Pediatrics. 87(4):281-286.

2. WHO. 2021. Update on coronavirus disease in Indonesia. Available at: 
https://www.who.int/indonesia/news/nove 1-coronavirus

3. Mahardhika GS, Tedjamartono TD, Buwono PW. 2021. High D-dimer and CRP Levels in an Asymptomatic COVID19 Patient: A Case Report and Brief Literature Review. Seminar Nasional Riset Kedokteran 2 (SENSORIK) 2021.

4. Abdelnasser MK, Morsy M, Osman AE. 2020. COVID-19. An update for orthopedic surgeon. SICOT-J. 6,24.

5. Gatot D, Mardia AI. 2018. Differences of wells scores accuracy, caprini scores and padua scores in deep vein thrombosis diagnosis. IOP Conf. Ser.: Earth Environ. Sci. 125012131

6. Wirabhawa M, Kawiyana KS, Suyasa IK, et al.2020. Hubungan dan titik potong skor Caprini terhadap D-dimer sebagai parameter resiko trombosis vena dalam pada pasien paska fiksasi internal fraktur tulang panjang ekstremitas bawah. Intisari Sains Medis. 11;1: 291-295.

7. Bagherifard, A., Arasteh, P., Salehpour, M. et al. COVID-19 among patients with orthopedic surgery: our experience from the Middle East. J Orthop Surg Res 16, 336

(2021).

https://doi.org/10.1186/s13018-02102483-6.

8. He X, Yao F, Chen J, Wang Y, et al. 2021. The poor prognosis and infuencing factors of high D-dimer levels for COVID-19 patients. Nature research. 11:1830.

9. Yao Y, Cao J, Wang Q, et al. 2020. Ddimer as a biomarker for disease severity and mortality in COVID-19 patients: a case control study. Journal of Intensive Care. 8:49

10. Liu C, Song Y, Zhao J, Xu Q, et al. 2016. Elevated D-dimer and fibrinogen levels in serum of preoperative bone fracture patients. SpringerPlus.5:161

11. Zhang LD, Liu HB, Li YN, Ma HM, et al. 2012. Correlation analysis between plasma D-dimer levels and orthopedic trauma severity. Chinese Medical Journal.125(17): 3133-3136

12. Zhou H, Hu Y, Li X, et al. 2018. Assessment of the Risk of Venous Thromboembolism in Medical Inpatients using Padua Prediction Score and Caprini Risk Assessment Model. J Atheroscler Thromb. 25:000-000.

13. Pannucci CJ, Swistun L, MacDonald JK, et al. Individualized Venous Thromboembolism Risk Stratification Using the 2005 Caprini Score to Identify the Benefits and Harms of Chemoprophylaxis in Surgical Patients: A Meta-analysis. Ann Surg. 2017;265(6):1094-1103

14. Decousus H, Tapson VF, Bergmann JF, et al. Factors at admission associated with bleeding risk in medical patients: findings from the IMPROVE investigators. Chest. 2011;139(1):69-79.

http://dx.doi.org/10.1378/chest.09-3081. PMid:20453069.

15. Falck-Ytter Y, Francis CW, Johanson NA, et al. Prevention of VTE in orthopedic surgery patients: antithrombotic therapy and prevention of thrombosis, 9th ed: American College of Chest Physicians Evidence-Based Clinical Practice Guidelines. Chest. 2012;141(2,Supl):e278S-325S. http://dx.doi.org/10.1378/chest.11-2404. PMid:22315265.

16. Spyropoulos AC, Douketis JD. How i treat anticoagulated patients undergoing an elective procedure or surgery. Blood. 2012; 120(15):2954-62. http://dx.doi.org/10.1182/blood-2012-06415943.PMID:22932800.

17. Dahl OE, Quinlan DJ, Bergqvist D, Eikelboom JW. A critical appraisal of bleeding events reported in venous thromboembolism prevention trials of patients undergoing hip and knee arthroplasty. J Thromb Haemost. 2010;8(9): 1966-75. http://dx.doi.org/10.1111/j.15387836.2010.03965.x. PMid:20586919.

18. WHO. 2020. Criteria for releasing COVID-19 patients from isolation. Available at: https://www.who.int/publications-detailredirect/criteria-for-releasing-covid-19patients-from-isolation

19. Spiezia L, Boscolo A, Poletto F, et al. COVID-19-related severe hypercoagulability in patients admitted to 
I Made Wira Kusuma et.al. High D-dimer level in fracture patient with asymptomatic Covid-19: dilemmatic surgery decision-a serial case report

intensive care unit for acute respiratory failure. Thromb Haemost. 2020;120(6):998-1000.

20. Lin C, Chen Y, Chen B, Zheng K, Luo X, Lin F. 2020. D-Dimer Combined with Fibrinogen Predicts the Risk of Venous Thrombosis in Fracture Patients. Emergency Medicine International (2020). 1930405, 7 pages

21. Levy G, Levy PY, Hessmann J, Monin P. Diagnosis of post-operative venous thrombosis using determination of plasma D-dimer. J Mal Vasc. 1998;23(4):269-267

22. Alberta V, Subramaniana A, Trikhab V, et al. 2018. Acute coagulofibrinolytic and inflammatory changes in response to intramedullary nailing and its impact on outcome. Journal of Clinical Orthopaedics and Trauma 9S. S67-S73

How to cite this article: I Made Wira Kusuma, I Made Iman Antariksa, Ida Bagus Gde Darma Wibawa et.al. High D-dimer level in fracture patient with asymptomatic Covid-19: dilemmatic surgery decision-a serial case report. International Journal of Science \& Healthcare Research. 2021; 6(4): 42-51. DOI: https://doi.org/10.52403/ijshr.20211007 